\title{
Traditional tales and contemporary art to promote multiple literacies
}

\author{
Morgan Schatz Blackrose and Roman W. Schatz \\ Schatz Blackrose Storytelling PO Box 60 Port Macquarie, NSW 2444 Australia www.schatzblackrose.com \\ Email story@schatzblackrose.com
}

\begin{abstract}
Storytelling-based arts projects offer a universal and inclusive pedagogy; challenging prejudices, celebrating diversity and promoting tolerance and resilience in participants. In addition they assist in the development of receptive and expressive language skills, provide a credible basis for understanding folklore, cultural traditions and social values, as well as offering a sound foundation for the pursuit of, and competency in, reading and writing. The contention that art and storytelling are global languages, lies at the heart of the storytelling based arts projects conducted by Australian storyteller, author and musician, Morgan Schatz Blackrose and Swiss Australian artist Roman W. Schatz.

\section{Introduction}

If you want your children to be intelligent, read them fairy tales. If you want them to be more intelligent, read them more fairy tales. Albert Einstein (1879-1955)

All children are artists. Pablo Picasso (1881 - 1973)

The first storytelling-based arts project we conducted was in 1996 at an Australian primary school that was undergoing extensions. As a result of the construction there was constant noise and the playground was reduced to rubble and mud, surrounded by a two-metre high security fence. All in all, it was a disruptive and sometimes distressing place for children to spend their days. We believed that implementing a storytellingbased arts project was a way for the children to transform their immediate environment and exert a semblance of control over what was happening.
\end{abstract}

In collaboration with the Parents Association we conceived the Web of Wonder, a month long project of storytelling and weaving with students that not only resulted in their creation of ephemeral textile sculptures on the fences, but helped in bolstering the morale of the school community. The project showed us that storytelling and art had the power to transform an environment, strengthen a community and empower individual participants.

Over the past six years we have conducted storytelling-based arts projects in International schools in Turkey, Germany, China, Belgium and South Korea. Combined performance and visual arts achieves a multitude of learning outcomes, particularly regarding multi-literacies. John O'Toole says that literacy isn't just about writing "but all the symbol systems, linguistic and otherwise, that mediate meaning, each with their own literacy demands" (O'Toole, Sinclair \& Jeanneret, 2008, p.31). He refers to multi-literacies as oracy (speaking and listening), literacy (reading and writing), visual literacy (reading and interpreting visual symbols), mathematical literacy, technological literacy, critical, social, aesthetic and functional literacy in each of the art forms (O'Toole, Sinclair \& Jeanneret, 2008, p.29).

While our storytelling-based arts projects cannot claim to address all of the literacies in the spectrum, it is our contention that every project effectively promotes oral, visual, social and cultural literacies, and specific projects attend to additional literacies.

Even though we refer to art and storytelling as global languages, meaning that everyone in the world can communicate in them, like all languages, they still have to be learnt! The children who participate in each storytelling-based arts project are at different levels of competency and comfort with these mediums of expression. Each project allows for children to participate regardless of English language or artistic proficiency.

(C) 2010 IASL, SLAQ and therein by the authors. Diversity Challenge Resilience: School Libraries in Action Proceedings of the $12^{\text {th }}$ Biennial School Library Association of Queensland, the $39^{\text {th }}$ International Association of School Librarianship Annual Conference incorporating the $14^{\text {th }}$ International Forum on Research in School Librarianship, Brisbane QLD Australia, 27 September - 1 October 2010. 
We adopt a collaborative and inclusive approach in the design and implementation of each project to ensure that the integrity of the artistic concept is adhered to, the specific outcomes required by the school are met, and most importantly, that each child will be able to have a positive creative experience. Our knowledge as arts practitioners, trust in the idealism and artistry of the children and flexibility in the execution and direction of the project, are integral to each project's success.

Most of the schools we visit invite different artists for a residency each year. However, there are schools that we return to annually, and one in South Korea has incorporated us into their curriculum. To date we have presented the following storytelling-based arts projects there: Book making, Printing, Textile Sculpture, Abstract art exhibition, ABCD (Aboriginal Boomerangs, Clapsticks and Didgeridoos) instrument making and concert and $I A M$, an exploration of identity incorporating text as visual art. Like many International schools they have an enrolment of children from over thirty different nationalities, so their preference is for inclusive arts projects with global perspectives.

Each residency is designed so that children of any age, culture and ability can participate, and stories are performed appropriate to the age of the students. Oral storytelling of traditional tales is the foundation for each residency. This means that all students from preschool to senior years participate in storytelling sessions or concerts. The stories relate to and or reflect the artistic concept of each project. Although we may offer the same project, the participants and school requirements determine its uniqueness, as shown in the following example of Come Fly With Me where students created a textile sculpture and explored the concept of flying.

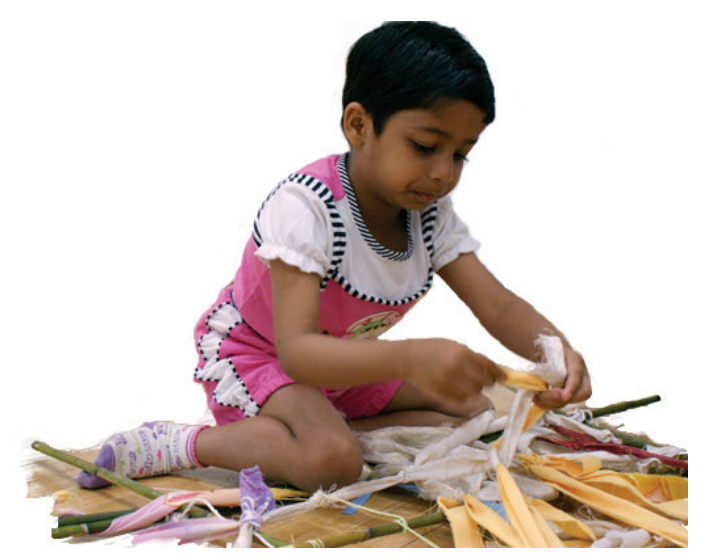

A young weaver working on creating a textile sculpture.

At a school in Turkey with mainly Turkish students, the project focused on weaving magic flying carpets and the telling of Turkish folktales; an affirmation of Turkish culture, particularly its folklore and craft. An exciting outcome of this project was a new interest expressed by the students in their own Turkish oral and cultural traditions. This was shown in their requests for material in the library collection and also whether there were Turkish speaking storytellers who could also visit the school.

At two international schools in South Korea the project involved the creation of bamboo wings, and the telling of folktales from many different cultures. As we like to position a project in the country it is undertaken in, we used bamboo in the construction of the wings. It is an iconic Asian plant and is commonly used in building construction as scaffolding. When older students were told the Greek myth of Daedalus and Icarus, they discussed the real possibility of flight with 'the wings.' Flight as both a metaphorical and literal concept was investigated and the notion of stories 'flying' from one culture or country to another was a useful takeoff point for discussions on cultural diversity and similarity.

The sharing of folktales is an ideal way of both affirming cultural diversity and discovering our common humanity. It is for this reason that the main genre of stories told in each project is folktales. Sometimes there is a specific cultural focus on the storytelling, but even in these projects, stories from various cultures and

(C) 2010 IASL, SLAQ and therein by the authors. Diversity Challenge Resilience: School Libraries in Action Proceedings of the $12^{\text {th }}$ Biennial School Library Association of Queensland, the $39^{\text {th }}$ International Association of School Librarianship Annual Conference incorporating the $14^{\text {th }}$ International Forum on Research in School Librarianship, Brisbane QLD Australia, 27 September - 1 October 2010. 
traditions are included to highlight the affinity between different peoples. While folktales may be specific to a culture because of their characters, animals and plants indigenous to the country of the story, the values promoted in the tale are often universal in their application.

In a residency with kindergarten children at an International school in Belgium, the storytelling focus was on Australian Aboriginal creation stories. Three kindergarten classes created storytelling scrolls; their visual interpretation of a specific Dreaming story. The project concluded with each class exhibiting their work and presenting a performance of the story to the school. While the Dreaming stories themselves were new to all of the children, many of whom were not familiar with the animals in the stories, the values of generosity, kindness and co-operation promulgated in the tales were tangible concepts that they could identify with.

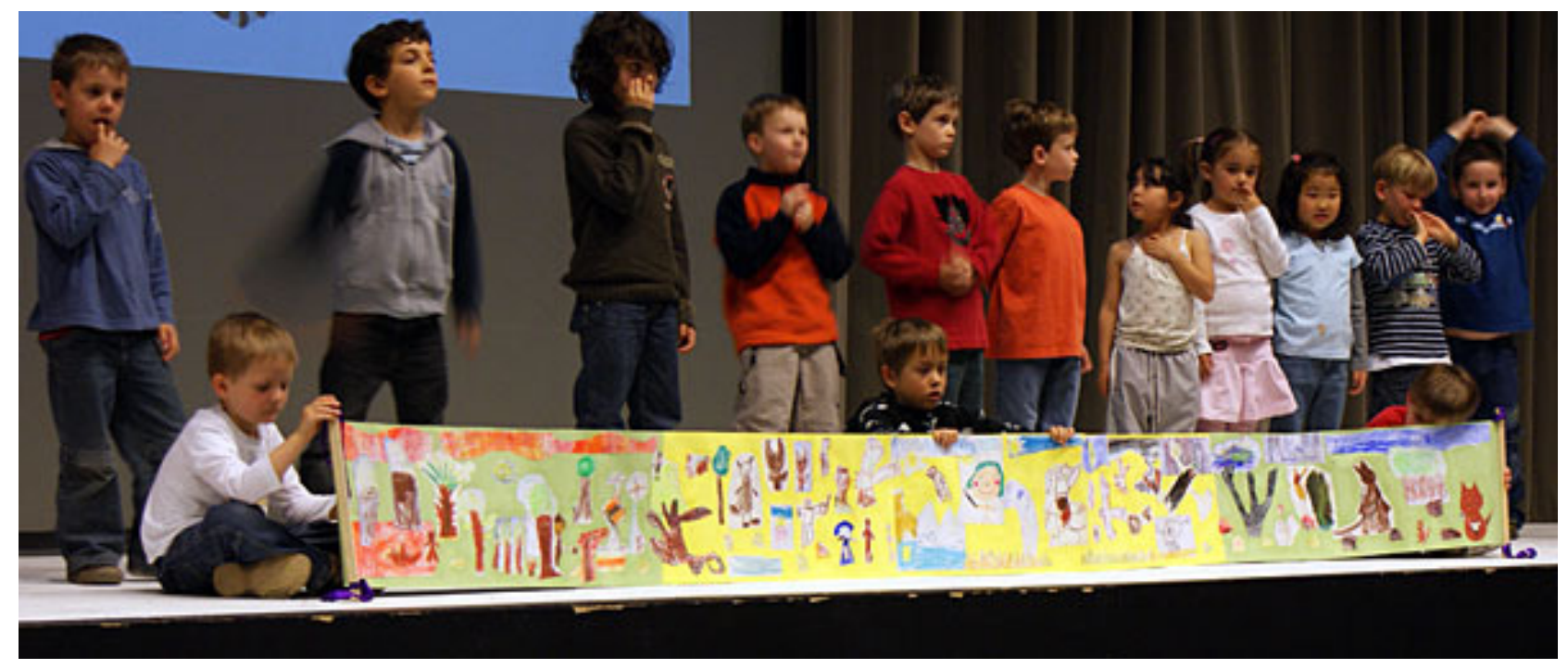

A kinder class displaying their scroll telling the Aboriginal creation story of how the kangaroo got her pouch.

The artistic medium of collaging allowed for every child's work, regardless of its 'merit', to be included in the scrolls. Inclusive processes ensure everyone participates and thereby has ownership of the work. Individually a child can claim ownership of their picture or instrument, but in collective creations it is also important for them to feel ownership. When they walk into the library and see a textile sculpture hanging on display they can say, 'we made that sculpture and there's the ribbon I tied on.' Or, in the case of the scrolls, 'we drew this and that blue bit there is my sky.' Libraries play an important role in displaying student artworks. This not only acknowledges the value of the work as being important enough to publicly display for everyone to see, but connects art and story through place; the library is a house of stories and the artwork is a visual story created by the students. Inclusion means that every project, in both visual and performing arts, must allow for degrees of participation, from the confident and capable to the reticent and inexperienced.

In $A B C D$ the didgeridoo players participated in a concert with one blow of their instrument! Aesthetically this was successful because of the performance design. It worked as a Gesamtkunstwerk; where all the components make up the complete work. In the four days leading up to the concert, students made their instruments and each class group participated in their own storytelling and music sessions. They then came together for the whole school concert, and each group had a specific role in the performance. Ashwin Jawalikar, a Year 6 student, described it,

On Friday, it was time for our performance. We brought our didgeridoos from the art room, and sat on the floor, in a square. We learned some signs from Morgan. When she pointed up, we had to put our didgeridoo upwards. When she pointed down, we had to be ready to play. We turned off the lights and the little kids came in. The Reception - Year 2 had clapsticks, and Year 3 had boomerangs. Then Morgan played the song and the Year 3 made a dance with the boomerangs, and the little kids

(C) 2010 IASL, SLAQ and therein by the authors. Diversity Challenge Resilience: School Libraries in Action Proceedings of the $12^{\text {th }}$ Biennial School Library Association of Queensland, the $39^{\text {th }}$ International Association of School Librarianship Annual Conference incorporating the $14^{\text {th }}$ International Forum on Research in School Librarianship, Brisbane QLD Australia, 27 September - 1 October 2010 . 
started playing the clap sticks. We remembered when we had to start to play, and it was brilliant. Everyone started playing weird sounds with their didgeridoos. Everyone loved it. (A letter from Hyundai Foreign School, 2009)

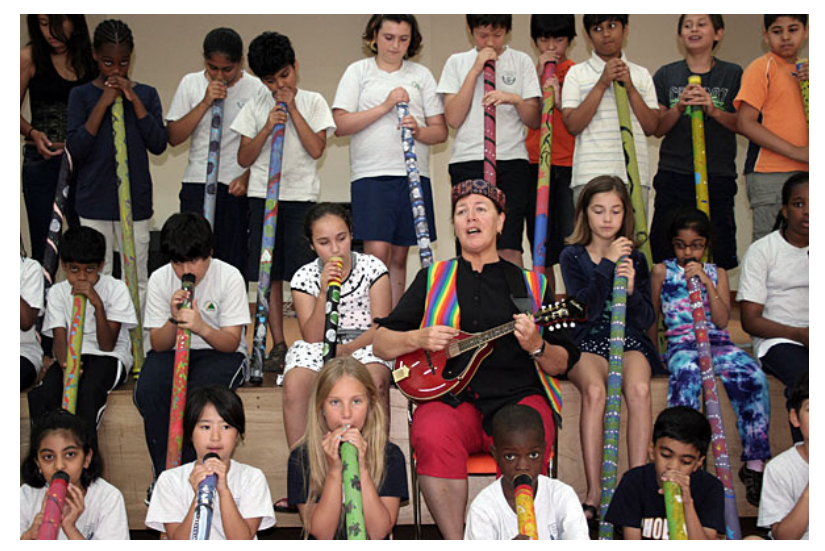

\section{Years $5,6 \& 7$ rehearse for the $A B C D$ concert}

The Shui Symphony, conducted at an International School in China, was another example of a Gesamtkunstwerk, incorporating storytelling, art making and music making, additionally, with reference to the particular units of study being undertaken by each class. We wanted a connecting theme for the project and came up with water, or 'shui' in Mandarin. In China the great rivers were and still are, integral to Chinese culture. The nature and cycle of water also offered many musical opportunities.

Each age group created and decorated their own musical instruments from recycled materials and PVC pipe. They learned a rap, rhyme or song about water and practiced different ways of performing it. The Shui Symphony residency culminated in the presentation of a concert that parents were invited to attend. The performance opened with my telling of a Chinese folktale about the creation of the four great rivers of China and from there linked to the offerings of each of the groups. Although each group was familiar with their own material, the performances of the other groups and how everything connected to create a whole work was new to them. With one 'quick run through' acting as a rehearsal for the concert, the students were both performers and audience in the event. The finale, largely improvised by the students working together as an orchestra, was a credible rendition of a rainstorm.

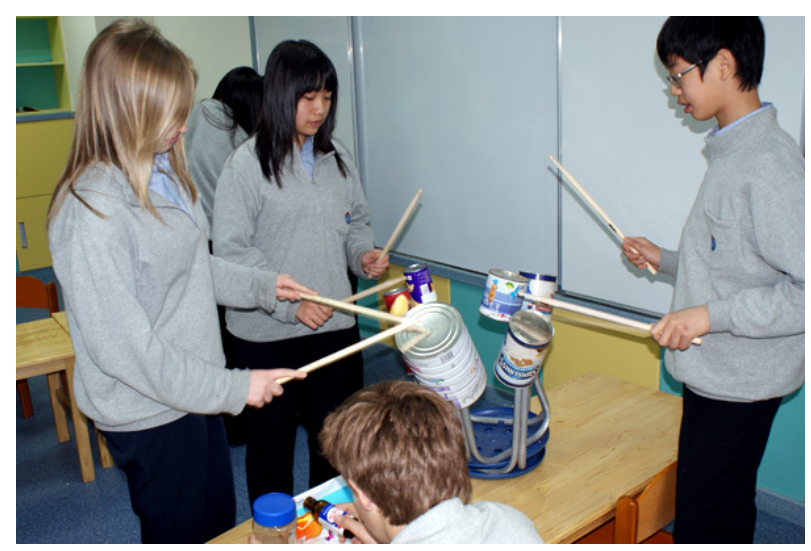

\section{Class experimentation with sound}

Interestingly, the school principal was surprised with the success of the performance, having been present in a morning workshop when the older students were experimenting with sound. He expressed his surprise in their transition from the morning's efforts to the afternoon's concert. Such 'doubts' are not unusual for someone observing the creative process of children 'playing' with art and music. How do sounds become

(C) 2010 IASL, SLAQ and therein by the authors. Diversity Challenge Resilience: School Libraries in Action Proceedings of the $12^{\text {th }}$ Biennial School Library Association of Queensland, the $39^{\text {th }}$ International Association of School Librarianship Annual Conference incorporating the $14^{\text {th }}$ International Forum on Research in School Librarianship, Brisbane QLD Australia, 27 September - 1 October 2010. 
music or marks become art? Exploration and experimentation are necessary for composition and creation, and what can appear as chaos, is often an active engagement in the art making and music making process. Neryl Jeanneret says,

The arts have the capacity to involve children as active participants in their own learning. When we present children with artistic problems we are asking them to reflect on their own reactions and engage in critical thinking, analysis and evaluation, rather than presenting them with what they should think (O'Toole, Sinclair \& Jeanneret, 2008, p.16).

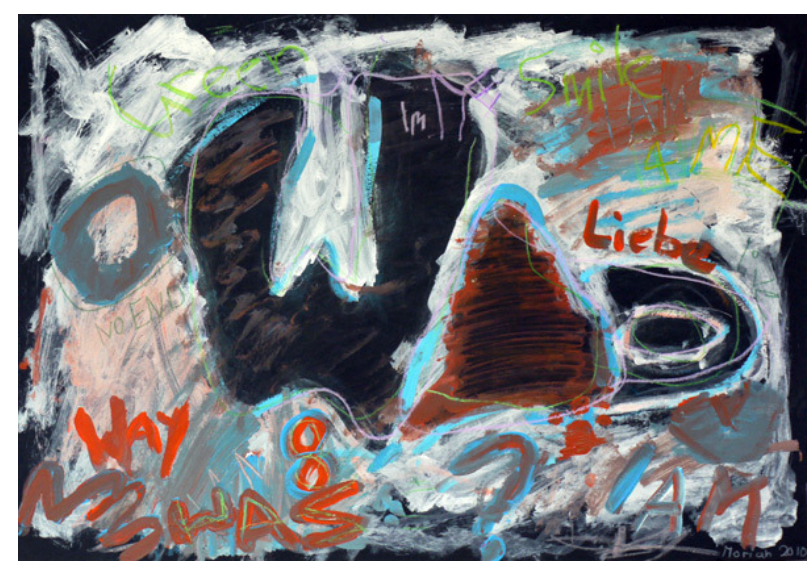

\section{An I AM artwork created by a Year 7 student}

The I AM project requires Middle School students to include text expressing their own thoughts and feelings in the creation of abstract expressionist works, and then to publicly speak about their artistic choices in the creation of their work; a challenging process for students in both artistic expression and oral presentation. However, their risk-taking proved worthy, with many students reporting a degree of achievement in both their creativity and overcoming their fears of public speaking. Many have not only produced exciting artworks but also some moving poetry.

While each project is highly structured to ensure the required outcomes for each school are met, the students' input determines the character and direction of the artistic outcome. Within each project there is the space for improvisation, collaboration and virtuosity of the participants.

Usually each residency is from two to five days, although we have also designed shorter projects. The Stone Soup workshop was part of the Folkways Day celebrations at an International School in Germany. Here the telling of a traditional story acted as a metaphor for participants to visually relate their dreams for a better world. These were then exchanged, expressed and exhibited among the school community. Participants included students, families and teachers who were encouraged to depict their dreams in whatever markmaking they felt comfortable with. Some did figurative pictures, others colours, some wrote in English and some wrote in their home language. Those that wanted to verbally share their dreams with others were encouraged to do so.

The statement by Jeanneret on the role of arts in reflecting cultural diversity is an important one. She says,

The arts convey the spirit, the beliefs, the social mores as well as the traditions and the contemporary ideas of the people who created them. The exposure of children to the arts in a variety of cultures can have a powerful impact on the way in which they think about those cultures and can equip them with inter- and intra-cultural understanding. ... learning in the arts provides children with the skills and knowledge necessary to understand how the arts reflect and depict the diversity of our world, its cultures, traditions, and belief systems, and to develop an understanding of cultural change and differences (O'Toole, Sinclair \& Jeanneret, 2008, p.17).

(C) 2010 IASL, SLAQ and therein by the authors. Diversity Challenge Resilience: School Libraries in Action Proceedings of the $12^{\text {th }}$ Biennial School Library Association of Queensland, the $39^{\text {th }}$ International Association of School Librarianship Annual Conference incorporating the $14^{\text {th }}$ International Forum on Research in School Librarianship, Brisbane QLD Australia, 27 September - 1 October 2010 . 


\section{Conclusion}

Through our residencies we attempt to both affirm cultural identity and promote tolerance, by inspiring children to (re)discover their own folkloric and artistic traditions as well as those of other cultures. However, when working with children from many different cultures it is important to find what they have in common. The most obvious shared experience is that of being human. As such, human beings feel emotions, and desire to express them through language and the arts. We believe that everyone has a story to tell and our primary purpose in the residencies is to facilitate the expression of the individual and collective stories of the participants. The oral telling of folktales is the foundation upon which all other forms of storytelling, that is, art making, music making, writing and performance, derive.

Traditional stories connect us to each other. They show us who we are, who we have been, and who we can become. Familiarising ourselves with our cultural stories promotes an understanding of both our identity and our humanity. Listening to the stories of others not only enriches our knowledge of the world and its peoples, it enables us to be more compassionate human beings. (Schatz Blackrose, 2008, p. 93)

Folktales are both the cultural heritage of all children and a rich resource that they can draw on to learn about the world. In the same way that the school librarian introduces the student to the stories housed in the library collection, it is our task as storytellers and artists to introduce traditional stories to children through our craft. Like the librarian, we foster the child's relationship with stories, assisting them to discover and express their own story through storytelling-based arts.

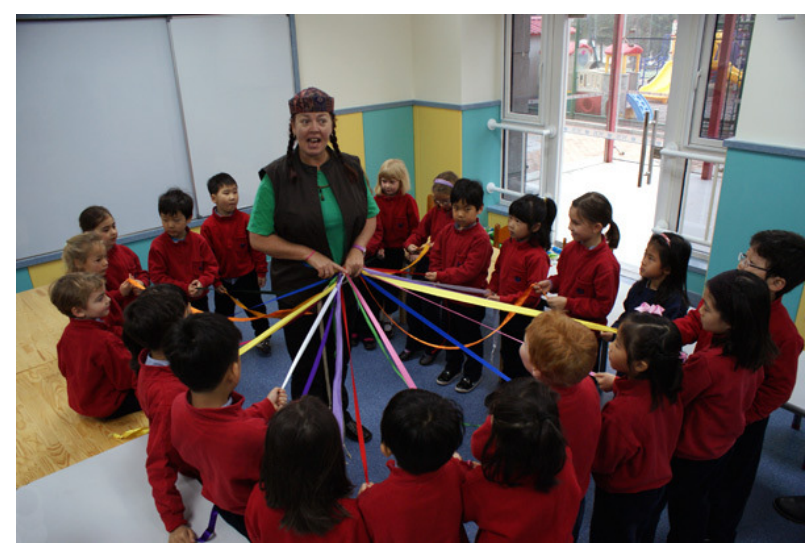

\section{Telling an Ananse folktale from Ghana with Grade 1}

Evaluating the success of each project is difficult. There are the required outcomes by the schools that are always met; such as a performance, a group sculpture, a painting exhibition, individual creation of books, instruments or prints. All these are readily identifiable achievements. Students writing their own reflections on the project are further indicators, if not necessarily of the projects' learning outcomes, certainly the response of the students' to the project. But how do you quantify the following participant outcomes that have come through our own observation, parent and teacher feedback and children's volunteered comments? Risk-taking, self-esteem building, co-operative behaviour, improvisation, active participation, considered thought, experimentation, attentive listening, group cohesion, activating the imagination, persistence and spontaneity. Perhaps it is appropriate to conclude with the final word from a storytelling-based arts project participant.

I liked the performance heaps and I think we did well. When the performance ended the story tellers had to go and I had a great time with them and I can't wait for next year.

(C) 2010 IASL, SLAQ and therein by the authors. Diversity Challenge Resilience: School Libraries in Action Proceedings of the $12^{\text {th }}$ Biennial School Library Association of Queensland, the $39^{\text {th }}$ International Association of School Librarianship Annual Conference incorporating the $14^{\text {th }}$ International Forum on Research in School Librarianship, Brisbane QLD Australia, 27 September - 1 October 2010 . 
Oskar O'Halloran Year 5 (A letter from Hyundai Foreign School, 2009)

Three key learnings:

- Storytelling-based arts are an inclusive way of addressing multi-literacies across different age levels.

- Storytelling-based arts can be adapted to meet the specific social and learning requirements of individual schools.

- Storytelling-based arts are a means of simultaneously celebrating cultural diversity, promoting internationalism and strengthening a school community.

\section{References}

O'Toole, J., Sinclair, C. \& Jeanneret, N. (eds.) (2008). Education in the Arts - teaching and learning in the contemporary curriculum. Melbourne, Australia: Oxford University Press.

Schatz Blackrose, M. (2008). Tell me, storytelling as a global language. Port Macquarie, Australia: Tell Me Books.

A Letter from Hyundai Foreign School (2009). Flik, foreign Life in Korea, 781, 6-17. 